\title{
O potencial educativo das praças como espaço educador sustentável
}

The educational potential of the spaces as a sustainable educator space

El potencial educativo de las plazas como un espacio sostenible educador

Gabriel Buffon do Amaral Especialista em Educação Ambiental e Espaços Educadores Sustentáveis - UFMS, Brasil. gabrielbuffonadv@hotmail.com

\section{Ricardo Miranda dos Santos}

Mestre em Geografia pela UFMS e Doutorando em Educação, Artes e História da Cultura - Universidade Mackenzie, Brasil ricardomiranda4@hotmail.com 


\section{RESUMO}

Compreendemos que um espaço educador é aquele que desenvolve a capacidade da sociedade em tornar-se também sustentável. O ambiente escolar em si, é, frequentemente, objeto de estudos por este enfoque na aplicação prática de projetos de educação ambiental. Todavia, outros espaços além da escola também podem ser alvo destes projetos e, atualmente, vêm ganhando espaço no campo teórico por demonstrarem seu potencial educacional e de conscientização social. Dentre eles, uma em especial ganha destaque, as praças. Isto se deve ao espaço privilegiado que a praça proporciona a seus usuários, com convivência entre várias gerações, seja por meio da prática de esporte, ou até mesmo pelo lazer propiciado. Esta transposição do espaço escolar possibilita que o estudante aguce seu olhar para o mundo, incentivando a curiosidade para a pesquisa e aprendizado sobre o meio ambiente. Atualmente, para despertar a curiosidade ambiental, não podemos nos prender aos limites dos espaços formais da sala de aula. Assim, sob o enfoque de tentar entender se há a formação, ou não, de um espaço educador sustentável na praça pública Marcílio Augusto Pinto - MAP, em Iguatemi/MS, o presente estudo, por meio da observação, diagnóstico dos equipamentos urbanos/paisagísticos, entrevista com seus frequentadores e confrontação destes com o referencial teórico levantado, identificou que o ambiente específico do estudo (Praça Marcílio Augusto Pinto) demonstrou um baixo potencial educativo na situação em que se encontra.

PALAVRAS-CHAVE: Espaço Educador. Educação Ambiental. Praça.

\section{Abstract}

We understand that an educational space is one that develops the capacity of society to become sustainable. The school environment itself is often studied by this approach in the practical application of environmental education projects. However, other spaces outside the school can also be the target of these projects and, currently, they have gained space in the theoretical field for demonstrating their educational potential and social awareness. Among them, one in particular stands out, the squares. This is due to the privileged space that the square provides its users, with coexistence between several generations, either through the practice of sports, or even by the leisure provided. This transposition of school space allows the student to sharpen his eyes on the world, encouraging curiosity for research and learning about the environment. Nowadays, to arouse environmental curiosity, we can not be trapped within the confines of formal classroom spaces. Thus, under the focus of trying to understand whether or not there is the formation of a sustainable educational space in the public square Marcílio Augusto Pinto - MAP, in Iguatemi / MS, the present study, through observation, diagnosis of urban / landscape equipment , Interview with its attendants and confrontation of these with the theoretical framework raised, identified that the specific environment of the study (Marcílio Augusto Pinto Square) showed a low educational potential in the situation in which it is found.

KEY WORDS: Space Educator. Environmental Education. Square.

\section{RESUMEN}

Entendemos que un espacio educador es el que se desarrolla la capacidad de la sociedad para convertirse en sostenible. El propio ambiente escolar, es a menudo el objeto de estudio de este enfoque en la aplicación práctica de proyectos de educación ambiental. Sin embargo, otros espacios más allá de la escuela también pueden ser objetivo de estos proyectos y en la actualidad están ganando espacio en el campo teórico para mostrar su potencial educativo y de sensibilización social. Entre ellos uno en particular se destaca, las plazas. Esto se debe al espacio privilegiado que el cuadrado ofrece a sus usuarios con la convivencia entre generaciones, ya sea a través de la práctica deportiva, o incluso el ocio que ofrece. Esta transposición del entorno escolar permite a los estudiantes agudizar su mirada en el mundo, alentando la curiosidad por la investigación y el aprendizaje sobre el medio ambiente. Actualmente, para aumentar la curiosidad del medio ambiente, no podemos mantenernos dentro de los límites de los espacios formales de la clase. Por lo tanto, desde el punto de vista de tratar de entender si existe o no la formación de un espacio educador sostenible en la plaza pública Marcilio Augusto Pinto - MAPA, en Iguatemi/MS, este estudio, a través de la observación, el diagnóstico de equipos / paisaje urbano entrevista con sus clientes y comparación de éstos con el teórico elevó identificó que el entorno específico del estudio (Pinto Marcilio Augusto Piazza) mostró un bajo potencial en la situación educativa en la que se encuentra.

PALAVRAS-CHAVE: Espacio Educador. Educación Ambiental. Plaza. Inicie o Texto em uma nova página 


\section{da Alta Paulista}

\section{INTRODUÇÃO}

Os espaços educadores, atualmente podem ser conceituados como espaços compostos por elementos essenciais e que se retroalimentam ou, ainda, como uma rede de lugares que se conectam e estimulam a sociedade a se tornar sustentável e justa. Desta forma, podem ser abrangidos como espaços educadores diversos ambientes coletivos, em especial as praças.

Estes ambientes podem vir a se tornar um ótimo agente transformador de hábitos e ideias, contribuindo significativamente para a evolução da consciência ambiental do todo (sociedade), basicamente, através da implantação de pequenos projetos voltados para esta finalidade. Com este enfoque, o presente trabalho procurará demonstrar que ações voltadas a estes ambientes podem repercutir exponencialmente na educação da sociedade como um todo.

A sociedade contemporânea convive hoje com muitos espaços de violência e desgastes nos laços relacionais e familiares. Como exemplos, referentes à perda do sentimento de pertencimento à cidade e ao desgaste dos laços fraternais destacam-se desde os assaltos, roubos, sequestros, homicídios, problemas de infraestrutura e serviços, transporte público, educação e saúde, até a falta de espaço de lazer, práticas desportiva e de convívio coletivo, consumismo, perda da ética e o respeito pelo próximo.

Desta forma, a utilização de espaços não formais ${ }^{1}$ ganha cada vez mais visibilidade na interligação do ensino e as modalidades pedagógicas que tem por finalidade um processo de aprendizagem cada vez mais significativo. Portanto a utilização do espaço da praça pública como instrumento de aprendizado, pode se tornar uma estratégia pedagógica que direciona uma reflexão sistêmica e holística da relação ser humano e natureza.

Nesse sentido, a presente pesquisa pretende compreender como a praça se constitui como um espaço de aprendizado e possa se tornar um espaço que educa por si só e com a intencionalidade educativa, ou seja, como um espaço educador sustentável. O artigo se estruturará em três partes: 1 ) compreender o conceito de espaço educador sustentável e sua estruturação nos espaços não formais de aprendizado; 2) A praça como instrumento pedagógico de aprendizado, na qual se evidencia a emergência de espaços educativos fora do ambiente escolar e que se possa caracterizar como espaço relacional; 3) Caracterização da praça pública Marcílio Augusto Pinto - MAP, em Iguatemi/MS como um espaço educador.

A metodologia consiste em análise documental, observação, diagnóstico dos equipamentos urbanos e paisagísticos da praça pública Marcílio Augusto Pinto - MAP da cidade de

\footnotetext{
${ }^{1}$ Esta pesquisa entende os conceitos de espaços formais, não formais e informais, segundo Chagas (1993, p.2). "A educação formal caracteriza-se por ser altamente estruturada. Desenvolve-se no seio de instituições próprias - escolas e universidades - onde o aluno deve seguir um programa prédeterminado, semelhante ao dos outros alunos que frequentam a mesma instituição. A educação nãoformal processa-se fora da esfera escolar e é veiculada pelos museus, meios de comunicação e outras instituições que organizam eventos do diversa ordem, tais como cursos livres, feiras e encontros, com o propósito do ensinar ciência a um público heterogêneo. A aprendizagem não formal desenvolve-se, assim, de acordo com os desejos do indivíduo, num clima especialmente concebido para se tornar agradável. Finalmente, a educação informal ocorre de forma espontânea na vida do dia-a-dia através de conversas e vivências com familiares, amigos, colegas e interlocutores ocasionais".
} 


\title{
da Alta Paulista
}

Iguatemi/MS, além de entrevistas com seus frequentadores. Houve a coleta de material por meio de aplicação de questionário voltado a 10 (dez) frequentadores da Praça Marcílio Augusto Pinto - MAP, bem como questionário específico a 04 (quatro) professores das Escolas Estaduais 8 de Maio e Marcílio Augusto Pinto, sendo que a primeira escola está localizada ao lado da praça.

Portanto, a pesquisa compreendeu a praça como instrumento pedagógico de aprendizado, restando evidenciado que as cidades precisam urgentemente repensar suas políticas públicas de urbanização e desenvolver espaços educativos dentro e fora do ambiente escolar.

Atualmente, o exemplo ao ser analisado sobre o conceito de espaços educadores sustentáveis, de forma específica são as escolas sustentáveis. Entretanto, de forma não tão distante, os espaços não formais vêm rompendo com o paradigma, deste ensino voltado tão somente para o conceito micro da sala de aula. Utilizaremos o conceito de "escola sustentável" como referêncial para compreender como a praça pode vir a se tornar um espaço educador sustentavel.

A transposição do espaço da escola possibilita que o estudante aguce seu olhar para o mundo, que por muitas vezes possui o conhecimento teórico, obtido por meio de imagens, leituras ou vídeos, e que limita, de certa forma, a curiosidade para a pesquisa e aprendizado sobre o meio ambiente.

Poder ofertar uma experiência teórica na prática é exigir do aluno a consciência das inúmeras possibilidades que ela proporcionará para sua aprendizagem. Dito isto é correto dizer que para despertar a curiosidade ambiental, hoje, não pode haver limites tão somente ao espaço formal da sala de aula.

\begin{abstract}
Muitas vezes somos levados a pensar que ensinar e aprender é uma viagem de ida e volta que se passa em sala de aula, na escola. A escola é o lugar social da educação. Esta é uma idéia correta, mas não inteiramente. A educação que vivemos na escola, como estudantes, como professores, como as duas "coisas" ao mesmo tempo, é uma fração importante de nosso aprendizado, mas não única. A educação escolar é um momento de um processo múltiplo, de vários rostos e vividos entre diferentes momentos, a que costumamos dar o nome de socialização (BRANDÃo, 2005, p.25).
\end{abstract}

Com este enfoque há que se perguntar: As praças, como ambiente coletivo, podem ser um espaço educador sustentável? As praças além dos aspectos relacionais também se constituem como espaços verdes da cidade, atraindo para si a responsabilidade de denotar aspectos estéticos e paisagísticos inerentes a cada cidade. Assim, é espaço crucial para atuação do educador ambiental, que deve passar a construir valores e estabelecer conexões entre o homem e o ambiente no qual ele está inserido.

Nós aprendemos, em diferentes e integradas dimensões de nós mesmo, os diversos saberes, as sensações, as sensibilidades, os sentidos, os significados e as sociabilidades que, juntas e em interação em nós e entre nós, nos tornam seres capazes de interagir com uma cultura e em uma sociedade (BRANDÃO, 2005, p.25).

Portanto, as praças podem irradiar sua influência à comunidade na qual esta inserida. Espaços não formais também podem ser espaços educadores com princípios para a sustentabilidade e, assim, passando a influenciar de modo positivo para manutenção e transformação da 
sociedade.

Todos os espaços que se dedicam à realização plena da educação, em todas as suas formas, podem ser chamados de espaços educadores. Um espaço educador é aquele que concretiza situações de ensino-aprendizagem intencionalmente, ou seja, espaços que assumem a responsabilidade de educar. Para alcançar esse objetivo, os espaços educadores dialogam com a realidade dos aprendentes e se constituem em referências de seus valores para a comunidade (BORGES, 2011, p.13).

Ao analisar o tema "praças" como espaço que irradia a intencionalidade educativa e sustentável, não podemos deixar de averiguar sobre sua espacialidade, bem como, suas representações e símbolos no contexto atual da sociedade.

Suas referências como agentes de novas relações sociais dependem de sua organização como um espaço colaborativo e relacional e de planejar uma estrutura urbana que são elos com os diversos espaços da cidade. Sendo assim, "uma cidade é repleta de espaços educadores e, a depender das políticas públicas e dos valores que as orientam, pode ser considerada um espaço educador [...]" (BORGES, 2011, p.13).

\section{OBJETIVOS}

O objetivo da pesquisa é identificar o potencial educativo da praça como formador de consciência ambiental do indivíduo que a utiliza e, assim, demonstrar que ações voltadas a espaços não formais podem repercutir exponencialmente na educação da sociedade como um todo. Pois, compreendemos a importância que o ambiente coletivo, em especifical as praças, tem sobre a formação de uma cultura, e neste caso, possa contribuir com o desenvolvimento da consciência ambiental ao estabelecer conexões entre os ambientes (praças) e as práticas pedagógicas educativas, culturais e as sociais.

\section{MÉTODO DE ANÁLISE}

Na tentativa de entender como se formam ou não espaços educadores sustentáveis, dentro ou fora dos projetos de educação ambiental, nas escolas ou em outros espaços, a metodologia consiste em análise documental, observação, diagnóstico dos equipamentos urbanos e paisagísticos da praça pública Marcílio Augusto Pinto - MAP da cidade de Iguatemi/MS, além de entrevistas com seus frequentadores. Neste ponto, foi utilizado o fluxograma abaixo para a entrevista com os professores: 


\section{da Alta Paulista}

Fluxograma 1: Para a realização da entrevista com os professores.

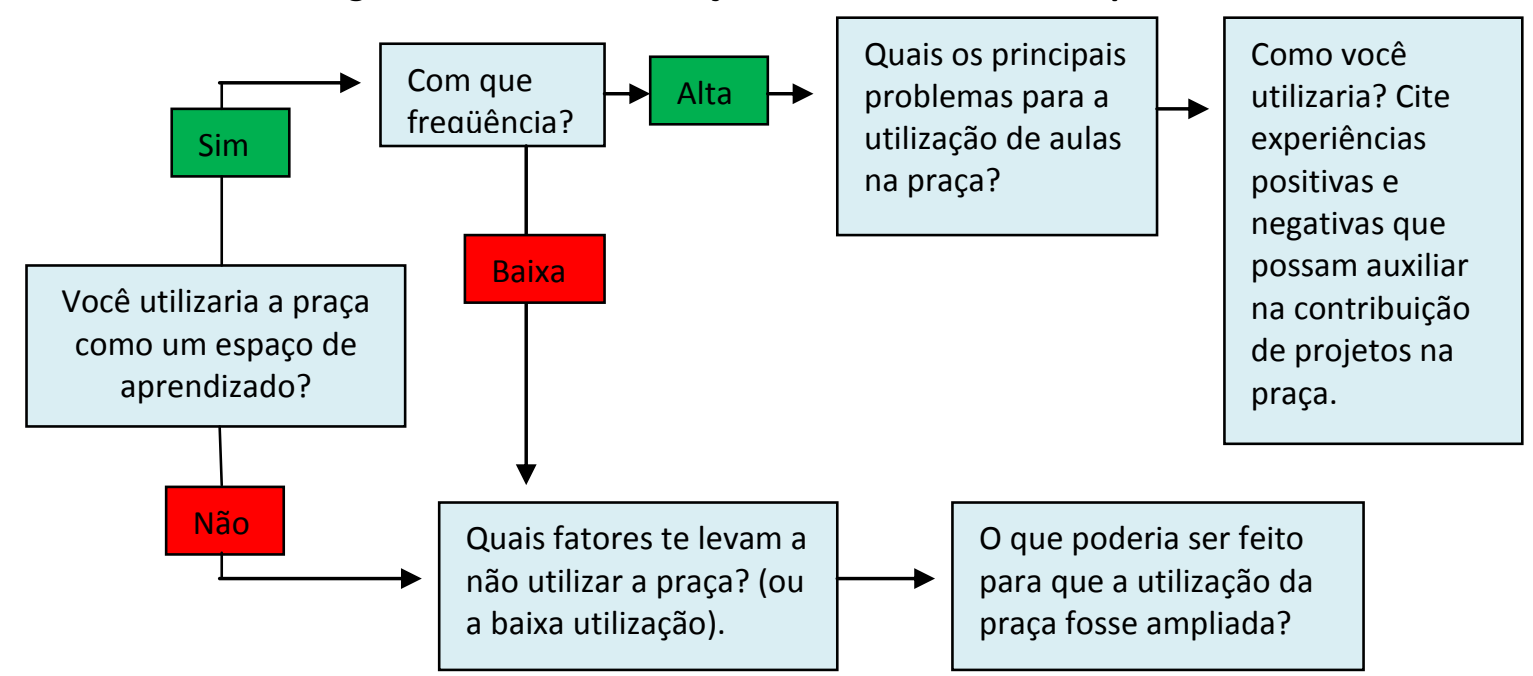

Fonte: Elaborado pelos autores.

O objetivo da entrevista era a obtenção de informações sobre a vontade do docente em utilizar, ou não, a praça como meio de ensino. Ato contínuo, baseado em seu grau de disponibilidade na utilização, compreender qual(is) o(s) motivo(s)os levariam a utilizar em maior ou menor grau e o que poderia ser feito ou aperfeiçoado naquele espaço para que fosse explorado cotidianamente como forma de ensino.

Com a coleta destes dados, houve a confrontação com o material teórico selecionado para que houvesse a conclusão do trabalho, com a finalidade de averiguar se os ambientes de aprendizados e sua gestão possuem princípios que favorecem ou não a constituição de espaços educadores sustentáveis.

A organização da observação, como um instrumento válido de investigação científica, baseiase em ter um controle sobre o que será observado e sistematizar em dados, devendo o pesquisador preparar o olhar para planejar o trabalho e observar o objeto de estudo. Desta forma, considerou os seguintes itens: 1) A função social das praças, a qual traceja historicamente como um espaço de construção cultural e relacional; 2) A praça como instrumento pedagógico de aprendizado, na qual se evidencia a emergência de espaços educativos fora do ambiente escolar e que se possa caracterizar como espaço relacional.

Ao observar, o pesquisador precisa determinar com antecedência "o que" e "o como" essa atividade será realizada. E delimitar o objeto de estudo é a sua primeira tarefa para que os aspectos do problema que a observação pretende investigar sejam revelados.

O objetivo é que o estudo da praça, com a observação, diagnóstico dos equipamentos urbanos e paisagísticos e entrevista com os seus frequentadores possam ser confrontados com o referencial teórico levantado. 
RESULTADOS

No espaço urbano temos inúmeros espaços não formais de aprendizados como: praças, parques, bibliotecas, museus entre outros. Segundo Bezerra, Lacerda Junior e Terán (2013, p.05) "os espaços das praças constituem-se como espaço privilegiado de encontros na cidade". A praça se constitui como um espaço de convivência entre gerações para a realização de inúmeras atividades desde lazer, à prática de esporte ou educativa.

Com o avanço das tecnologias e novas formas de interação, espaços relacionais como as praças, atualmente, se constituem ambientes estratégicos para estabelecer os vínculos sociais. As praças além dos aspectos relacionais também se constituem com espaços verdes da cidade, muitas vezes responsável pelos aspectos estéticos paisagísticos da cidade.

Desta forma, as praças são espaços privilegiados para atuação do educador ambiental para construção de valores e estabelecer conexões entre o homem e o ambiente. O Educador Ambiental como um Educador Social assume uma postura diante dos dilemas contemporâneos com o compromisso de "transmitir um conjunto de normas, valores e regras, mas também atua no sentido de preparar os educandos para lidar com seus sofrimentos, conflitos e tensões, buscar sua libertação e a de seus companheiros" (SOUZA NETO, 2010, p.30).

O conceito de "Espaços Educadores Sustentáveis" está alicerçado na definição de "Escolas Sustentáveis", sendo definido pelo Ministério do Meio Ambiente por meio da Resolução CD/FNDE no18, de 21 de maio de 2013, ao publicar o "Manual de Escolas Sustentáveis" com a finalidade de incentivar a instituições de ensino a desenvolverem e financiar projetos de pesquisa e intervenção em escolas da educação básica com vistas à criação de espaços educadores sustentáveis (BRASIL, 2013).

\footnotetext{
Escolas sustentáveis são definidas como aquelas que mantêm relação equilibrada com o meio ambiente e compensam seus impactos com o desenvolvimento de tecnologias apropriadas de modo a garantir qualidade de vida às presentes e futuras gerações. Esses espaços tem a intencionalidade de educar pelo exemplo e irradiar sua influência para as comunidades nas quais se situam. A transição para a sustentabilidade nas escolas é promovida a partir de três dimensões interrelacionadas: espaço físico, gestão e currículo (BRASIL,2013).
}

Portanto, seguindo esses princípios da escola sustentável como espaço que irradia sua influência na comunidade na qual esta inserida, espaços não formais também podem ser espaços educadores com princípios para a sustentabilidade e influenciar de modo positivo para manutenção e transformação da sociedade.

Segundo Gadotti (2012, p.24), "é sabido, contudo, que a educação não é o agente fundamental da mudança no interior da sociedade capitalista. Mas é sabido também que ela tem um peso nessa mudança".

Contudo, "nenhum espaço social pode estar fora dessa rede que tece o compromisso com um planeta que é a casa em que vivemos e que vamos deixar de legado às futuras gerações" (BORGES, 2011, p.03). A autora entende que "uma cidade é repleta de espaços educadores e, a depender das políticas públicas e dos valores que as orientam, [...] cria oportunidades de convivência, propiciando o surgimento de comunidades de aprendizagem" (BORGES, 2011, 
p.13).

Assim, Trajber e Sato (2010, p.72) ressaltam que esses espaços possuem princípios caracolianos "[...] como uma espiral de possibilidades e descobertas e por apresentar uma proposta de aprendizagem circular, que não se fecha e permanece inacabada na incompletude de avançar e recuar; de ensinar e aprender". As autoras consideram que as escolas sustentáveis são "o território é o espaço que constrói as identidades" é o currículo tem um papel fundamental a desempenhar na formação do sujeito. Os espaços não formais, como as praças, também podem se constituir como território onde as identidades são formadas.

Resumidamente as escolas sustentáveis, assim como os demais espaços não formais de aprendizados, visam desenvolver suas práticas com projetos socioambientais que envolvam os estudantes e a comunidade para promover o diálogo entre os saberes locais e tradicionais com os culturais e científicos.

Portanto, a Educação Ambiental e os Espaços Educadores Sustentáveis vistos como uma política pública preocupada com o futuro do planeta e da sociedade organiza-se para que os espaços educadores sejam referências de sustentabilidade para a comunidade, promovendo mudanças de comportamento e formas de se relacionar com os espaços e as pessoas.

Os espaços podem ser idealizados visando estimular a convivência e a cooperação entre as pessoas. Nesta perspectiva que Trajber e Sato $(2010$, p.75) enfatizam que "repensar o ambiente, no sentido de torná-lo integrador, educador e sustentável, implica sua adequação em termos arquitetônicos, isto é, redesenhar os espaços de acordo com novas finalidades".

Desta forma, as praças e parques podem ser um espaço acolhedor para promover o aprendizado e possuir princípios de sustentabilidades incorporados nas suas edificações. Entende-se que os espaços escolares e/ou outros espaços não escolares podem promover ahumanizaçãodas relações por seconstituíremem espaço de convivência atrelado ao desenvolvimento do sujeito social. A educação social contribui na compreensão de como esses espaços podem ser constituídos.

\begin{abstract}
A educação social busca propiciar ao sujeito o encontro do verdadeiro sentido do ético, do estético, do belo e apresentar-Ihe modelos de valores humanos universais. Mais do que um instrumento socializador, a educação social é um meio de humanizar as relações, de levar o sujeito a compreender sua história, a agir eticamente em certas circunstâncias e a transformar a realidade social. A consciência adquirida nesse processo é obtido pela enfrentamento de uma sucessão de paradoxos e contradições, que permite a elaboração de uma ética que ultrapassa o sentido técnico e metodológico (SOUZA NETO, 2010, p.37-38).
\end{abstract}

Os espaços educadores sustentáveis se constituem como locais que têm a intencionalidade de humanizar as relações, por isso devem ser acolhedores a fim de estimular o convívio, aproximação cultural e dirimir os conflitos sociais.

Esses espaços são carregados de intencionalidades na produção de um saber e os gestores possuem uma preocupação com esse item, por considerar que a escola e outros espaços de aprendizado podem ser um exemplo de sustentabilidade e suas edificações e equipamentos urbanos eficientes para promover a economia dos recursos naturais.

Nas palavras de Leff $(2009$, p.17) entende-se por sustentabilidade como saber ambiental: 
O saber ambiental integra o conhecimento racional e o conhecimento sensível, os saberes e os sabores da vida. [...] Dessa forma, restaura-se a relação entre a vida e o conhecimento. $O$ saber ambiental reafirma o ser no tempo e o conhecer na história; estabelece-se em novas identidades e territórios de vida; reconhece o poder do saber e da vontade de poder como um querer saber. $O$ saber ambiental faz renascer o pensamento utópico e a vontade de liberdade em uma nova racionalidade na qual se fundem o rigor da razão e os excessos do desejo, a ética e o conhecimento, o pensamento racional e a sensualidade da vida. [...] O saber ambiental, interrompido pela incompletude do ser, pervertido pelo poder do saber e mobilizado pela relação com o Outro, elabora categorias para apreender o real desde o limite da existência e do entendimento, a diferença e a outredade. Dessa maneira, cria mundos de vida, constrói novas realidades e abre o curso da história para um futuro sustentável.

Para Moreira (2011, p.7) os espaços educadores sustentáveis possuem a "intencionalidade de educar para novas formas de convívio em sociedade e com a natureza, a edificação escolar tem a potencialidade de educar por si [...]". As edificações e os espaços escolares por serem projetos pensando nos princípios da sustentabilidade promovem uma reflexão de uso nos alunos, e para a autora "[...] revelando nos ambientes criados as premissas do cuidado com as pessoas e com o ambiente". Algo que, por si só, tem poder multiplicador, "como uma janela de possibilidades que se abre, trazendo alento e esperança para as localidades onde se situam" (MOREIRA, 2011, p.17). Nesta perspectiva, as praças e outros espaços de aprendizados podem se constituir como um ambiente de reflexão, que eduquem para o convívio, pois para se atingir os pressupostos e princípios da sustentabilidade, outros espaços, além da escola, devem irradiar para comunidade, como exemplos.

Houve a coleta de material por meio de aplicação de questionário voltado a 10 (dez) frequentadores da Praça Marcílio Augusto Pinto - MAP, bem como questionário específico a 04 (quatro) professores das Escolas Estaduais 8 de Maio e Marcílio Augusto Pinto, sendo que a primeira escola está localizada ao lado da praça objeto do estudo.

Os questionários foram aplicados em 14 a 17 de novembro de 2016, apurando-se que a idade dos usuários da praça varia de 21 (vinte e um) até 67 (sessenta e sete) anos, sendo destes 03 (três) homens e 07 (sete) mulheres. Já quanto aos professores, ministravam aulas de língua portuguesa, ciências, geografia e história, estando em sala de aula, em média, há 07 (sete) anos.

Dos dados coletados, pode-se observar que $80 \%$ (oitenta por cento) de seus frequentadores são residentes da cidade há mais de 05 (cinco) anos, possuindo vínculo histórico-afetivo com aquele local, uma vez que o frequentam/utilizam com frequência. Ainda, há que ser frisado que, dentre estes mesmos entrevistados, $80 \%$ (oitenta por cento) afirmaram utilizar a praça para lazer e prática de esporte, enquanto $20 \%$ (vinte por cento) utilizam para o fim de bem estar, incorporando ao seu dia-a-dia o hábito de frequentar este espaço público.

Quanto à avaliação dos equipamentos urbanos que estruturam a praça, a avaliação da quase totalidade dos frequentadores, cerca de 90\% (noventa por cento), foi "SATISFATÓRIA", sendo que os entrevistados apontaram itens que precisam ser melhorados como: falta de bebedouros, implantação de banheiros públicos em condições de uso e com acessibilidade às 
pessoas com deficiência e, sinalização adequada ou de fácil compreensão em todas as áreas da praça, frisando também que os equipamentos existentes estão precários e não recebem manutenção regularmente, sendo, ainda, vítima de depredação frequentemente (Figuras 01).

Figura 01: Imagens da praça que demonstram a existência de lixeiras, bancos, mesas de xadrez e chuveiro para saída da quadra de areia, porém, totalmente sem qualquer manutenção.
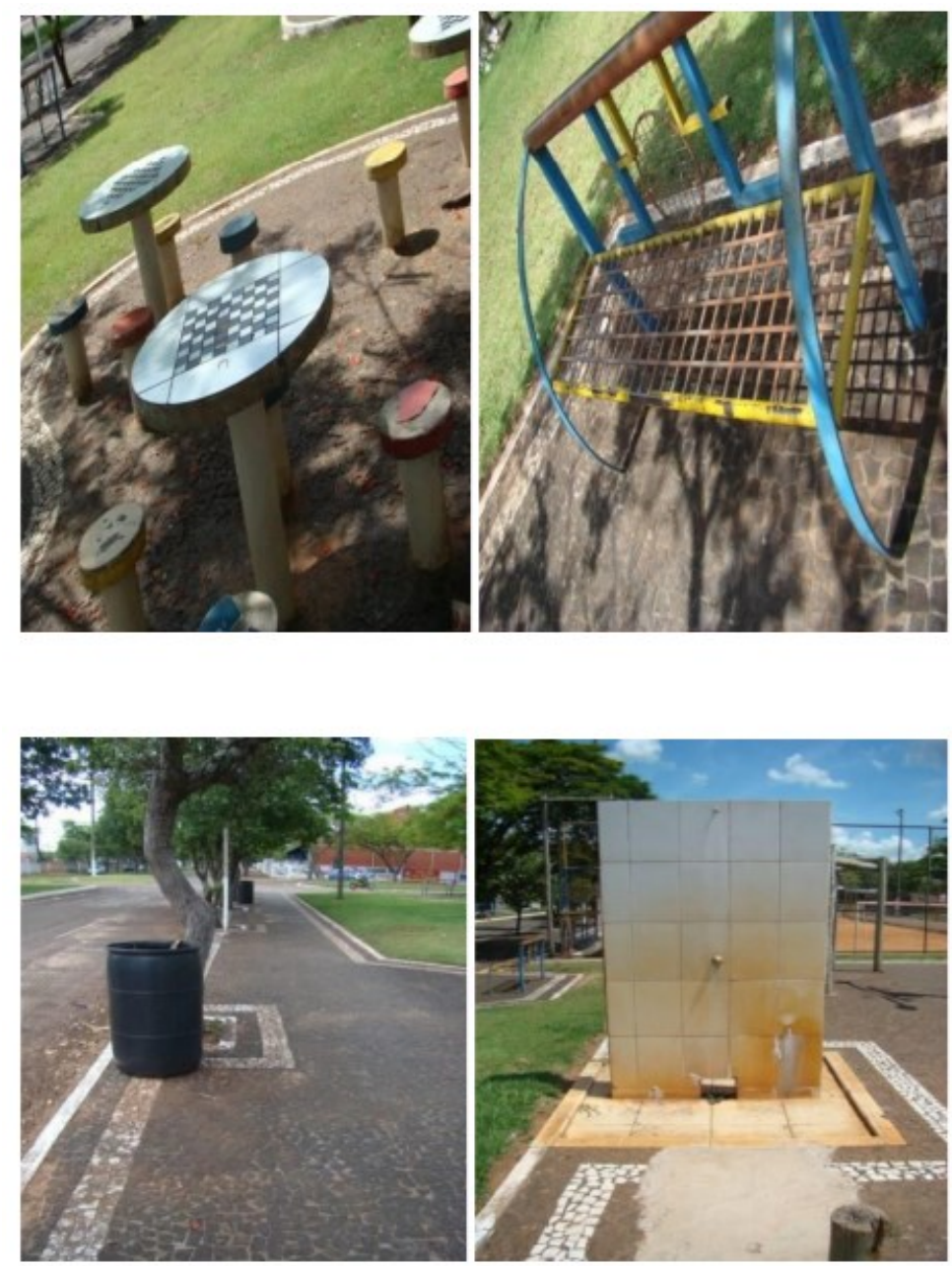

Fonte: Próprio autores - Visita de campo.

Não distante, os $10 \%$ (dez por cento) que consideraram a praça como "BOA" enfatizaram que poderia estar mais bem estruturada caso houvesse manutenção periódica na iluminação do local e, também, se existissem banheiros públicos de fácil acesso, relatando que os que existem no local são de uso comum dos quiosques que comercializam produtos alimentícios dentro do próprio ambiente da praça (Figura 02). 
Figura 02: Um dos quiosques localizados dentro do espaço da praça.

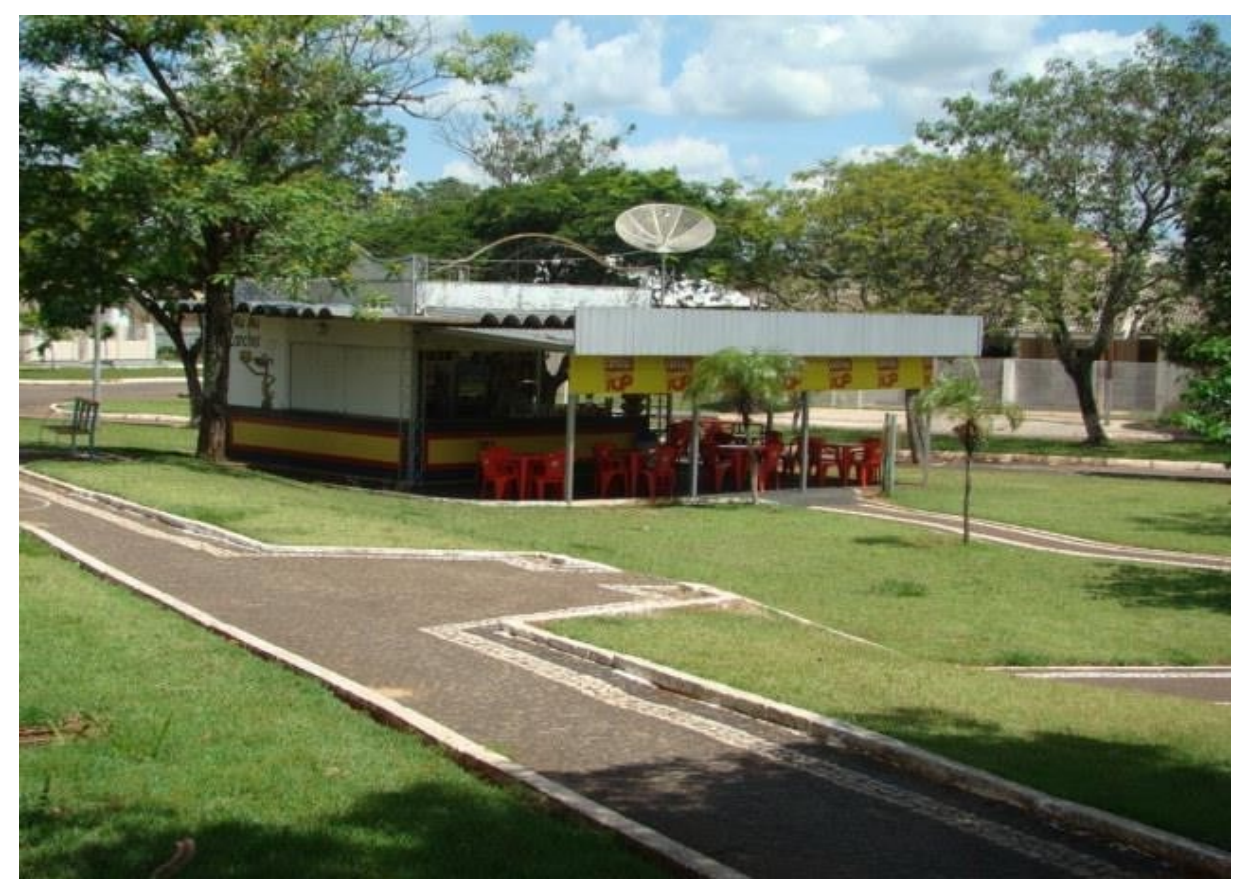

Fonte: Próprio autores - Visita de campo.

Curiosamente, embora tenha havido o apontamento da falta de alguns equipamentos na praça, cerca de $90 \%$ (noventa por cento) de seus usuários foram concisos em afirmar que àquele local proporciona um espaço relacional, ou seja, propício a prática de atividades de lazer (Figura 03), sendo por vezes citado como exemplos a reunião entre colegas para se tomar o "tereré" (bebida servida gelada e típica desta região fronteiriça), bem como para a prática do "vôlei de final de semana" (o qual serve como momento de descontração), reforçando, com isto, o fato que aquele ambiente é entendido como um estimulador na preservação da cultura local, bem como dememória. 


\section{da Alta Paulista}

Figura 03: À esquerda quadro de areia utilizada nos "Torneios entre casais" e aos finais de semana por seus usuários; à direita chafariz central da praça, hoje desprovido de iluminação e jatos de água.
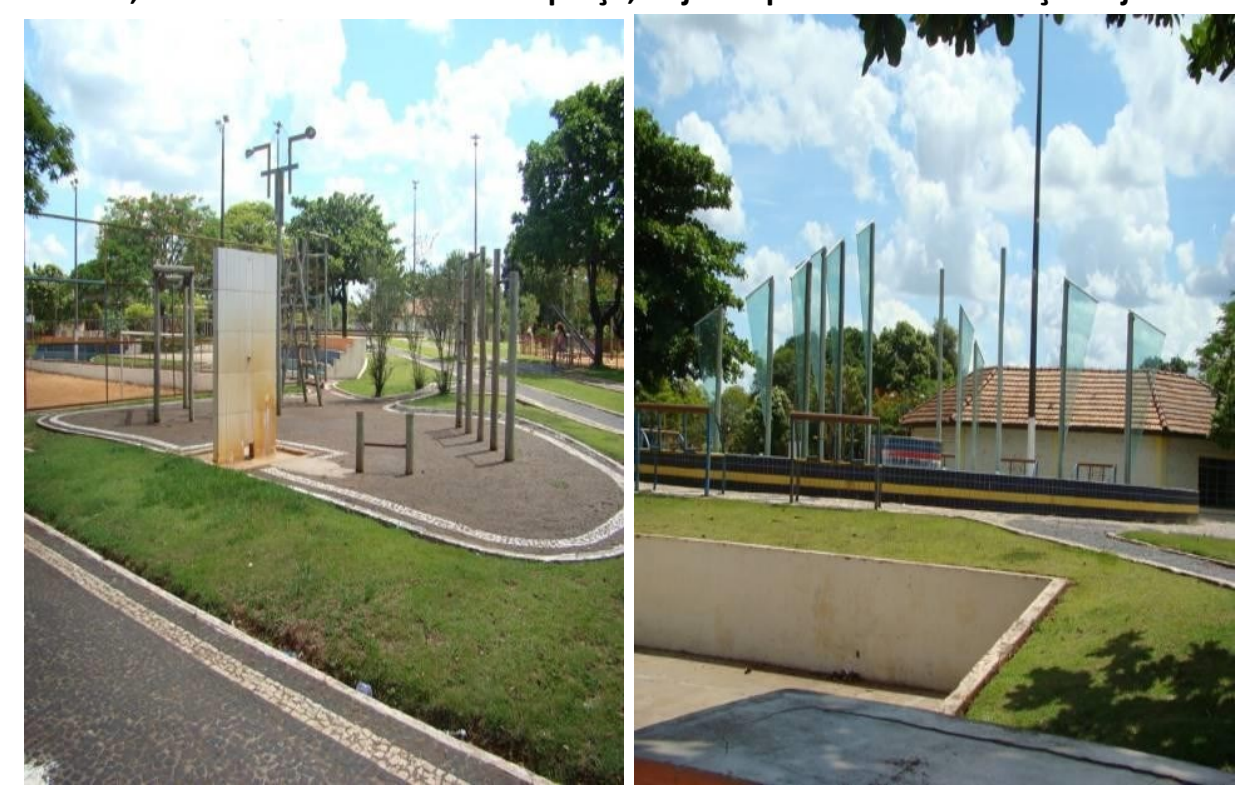

Fonte: Próprio autores - Visita de campo.

Quando abordados sobre a existência de possível potencial educativo a $80 \%$ (oitenta por cento) dos frequentadores e $75 \%$ (setenta e cinco por cento) dos professores ouvidos foram firmes em elencar que a praça é um local passível de desenvolvimento de práticas sustentáveis e educativas, argumentando que existe no local uma Biblioteca Municipal (Figura 04), à qual foi grandemente utilizada à época em que não se existia internet, ou sua utilização era de difícil acesso, estando, entretanto, "jogada às traças" atualmente.

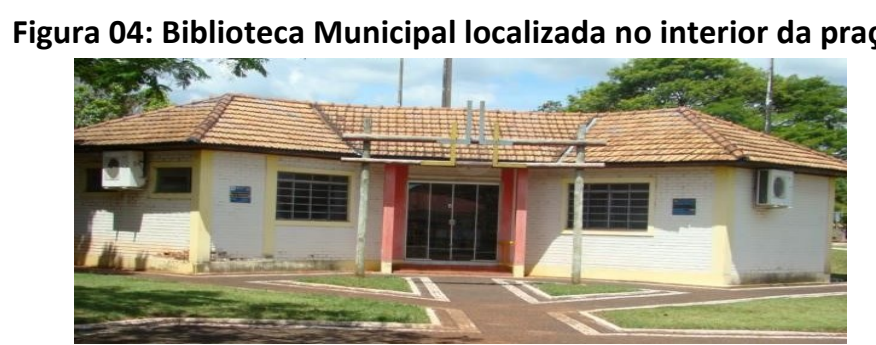

Fonte: Próprio autores - Visita de campo.

De igual forma $90 \%$ (noventa por cento) dos frequentadores e $100 \%$ (cem por cento) dos professores, acredita que, havendo interesse, a praça se tornaria um excelente palco de aprendizado, estimulando as mentes mais jovens e incentivando uma busca pelo conhecimento e sustentabilidade.

Desta forma foi relatado que, algumas vezes ao ano, a praça é utilizada como ambiente integrativo da comunidade através de evento denominado "Vôlei entre casais". Não bastasse tanto o município como algumas igrejas da cidade utilizam o espaço do "palco a céu aberto" (Figura 05) existente na praça para apresentações e amostras culturais, que, por serem 


\section{da Alta Paulista}

gratuitos, recebem uma quantidade considerável de expectadores.

Figura 05: Palco a céu aberto.

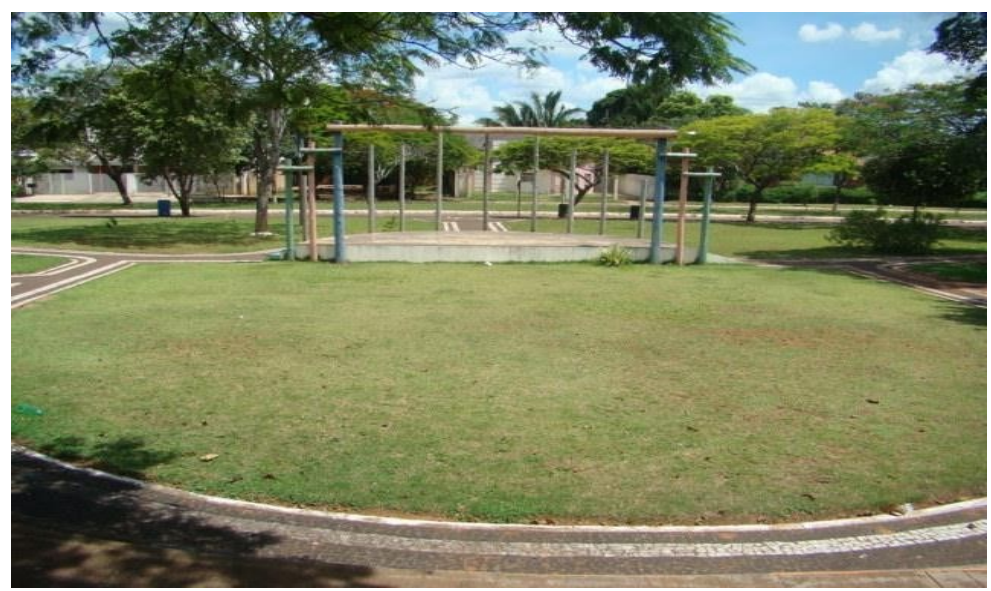

Fonte: Próprio autores - Visita de campo.

Ainda, por meio de material obtido na rede mundial de computadores, a própria praça já foi palco de Gincana para conscientização sobre o uso racional da água, promovida pela Empresa de Saneamento de Mato Grosso do Sul - SANESUL.

\section{CONCLUSÃO}

Primeiramente procurou-se conceituar as praças como um espaço não formal de conscientização social, espaços estes considerados privilegiados para atuação do educador ambiental, onde assume uma postura diante dos dilemas contemporâneos, devendo transmitir valores e regras que nortearão os indivíduos em suas atividades, com condão de conscientização ambiental.

Em continuidade demonstrou-se a praça como instrumento pedagógico de aprendizado, evidenciando a emergência de espaços educativos fora do ambiente escolar. Enfatizou-se que esta transposição do espaço escolar é necessária para aguçar o olhar do estudante para o mundo, sem deixar de frisar que estes espaços educadores dependem muito das políticas públicas e dos valores que as orientam.

Por meio da análise do material coletado, foi possível identificar que o ambiente específico do estudo (Praça Marcílio Augusto Pinto) demonstrou um baixo potencial educativo na situação em que se encontra. O principal fator que contribuiu para esta conclusão foi a demonstração por meio de questionário da falta de material físico hábil a persuadir o interesse dos educadores daquela localidade, sendo elencado pelos entrevistados " $n$ " pontos de melhorias necessárias para que este fim fossealcançado.

Em contrapartida, o mesmo estudo demonstrou que, quando estes ambientes se encontram em condições contrárias àquelas detectadas em primeira mão, ou seja, atendidas as exigências necessárias, com a reformulação do espaço e adequação da estrutura física 


\section{da Alta Paulista}

ofertada (havendo a disponibilização de um ambiente com oferta de banheiros públicos adequados, bebedouros aptos a suprir a demanda de seus usuários, dentre outros), o espaço da praça teria potencial suficiente para se tornar um espaço educador.

Desta forma, alcançando o objetivo da pesquisa, é possível dizer que um ambiente não formal como a praça, havendo as condições certas, é capaz de se tornar um espaço educador capaz de formar a consciência ambiental de seus usuários.

\section{REFERÊNCIAS BIBLIOGRÁFICAS (Calibre 11 - Negrito)}

BEZERRA, Alberto de Souza; LACERDA JUNIOR, José Cavalcante; TERÁN, Augusto Fachin. A praça como espaço não formal para a alfabetização ecológica. Disponível em:

<file:///D:/Meus\%20documentos/Downloads/2013_A\%20pra\%C3\%A7a\%20como\%20espa\%C3\%A7o\%20n\%C3\%A3o \%20formal\%20para\%20a\%20alfabetiza\%C3\%A7\% C3\%A30\%20ecol\%C3\%B3gica.pdf>. Acessado em 26 de setembro de 2016.

BRANDÃO, Carlos Rodrigues. Comunidades Aprendentes. In.: Encontros e caminhos de educadoras(ES) ambientais e coletivos educadores. Luis Antonio Ferraro Junior (Org.). Brasília: MMA. Diretoria de Educação Ambiental. 2005.

BORGES, Carla. O que são Espaços Educadores Sustentáveis. In.: Espaços Educadores Sustentáveis. TV ESCOLA/ SALTO PARA O FUTURO. ISSN 1982 - 0283. Ano XXI Boletim 07 - Junho 2011.

BRASIL. Resolução CD/FNDE no 18 de 21 de maio de 2013. Manual de Escolas Sustentáveis. Ministério da Educação. Secretaria de Educação Continuada, Alfabetização, Diversidade e Inclusão. Diretoria de Políticas de Educação em Direitos Humanos e Cidadania. Coordenação-Geral de Educação Ambiental. Disponível em:

<http://www.seduc.pi.gov.br/arquivos/1857975698.manual_escolas_sustentaveis_v_0 4.06.2013.pdf>. Acessado em 12 de dezembro de2015.

CHAGAS, I. (1993). Aprendizagem não formal/formal das ciências: Relações entre museus de ciência e escolas. Revista de Educação. 3 (1), 51-59. Lisboa. Disponível em: <http://www.ie.ulisboa.pt/pls/portal/docs/1/298079.PDF>. Acessado em 16/11/2016.

GADOTTI; Moacir. EDUCAÇÃO POPULAR, EDUCAÇÃO SOCIAL, EDUCAÇÃO COMUNITÁRIA: Conceitos e práticas diversas, cimentadas por uma causa comum. In: CONGRESSO INTERNACIONAL DE PEDAGOGIA SOCIAL, 4., 2012, São Paulo. Associação Brasileira de Educadores Sociais. Disponível em: <http://www.proceedings.scielo.br/pdf/cips/n4v2/13.pdf>. Acessado em 31 de maio de2016.

LEFF, Enrique. Complexidade, Racionalidade Ambiental e Diálogo de Saberes. Educação \& Realidade - ISSN 01003143 (impresso) e 2175-6236 (online). v. 34, n. 32009. Disponível em:

<http://seer.ufrgs.br/index.php/educacaoerealidade/article/view/9515/6720>. Acessado em 13 de junho de 2016.

MOREIRA, Tereza. Espaços Sustentáveis: Currículo, Gestão e Edificação. In.: Espaços Educadores Sustentáveis. TV ESCOLA/ SALTO PARA O FUTURO. ISSN 1982 - 0283. Ano XXI Boletim 07 - Junho 2011.

SOUZA NETO, João Clemente. Pedagogia Social: A formação do Educador Social e seu campo de atuação. Cadernos de Pesquisa em Educação Social PPGE-UFES. Vitória. V.16. n.32. p.29-64. Jul/dez.2010.

TRAJBER, Rachel. SATO, Michèle. Escolas Sustentáveis: Incubadoras de Transformações nas Comunidades. Rev. eletrônica Mestr. Educ. Ambient. ISSN 1517-1256, v. especial, setembro de 2010. 